\title{
LISTERIOSE NA GESTAÇÃO: INCIDÊNCIA DE INFECÇÃO EM GESTANTES DEVIDO À BAIXA IMUNIDADE
}

\author{
Carla Monique Araújo \\ José Onício Rosa da Silva \\ Sandra Regina Afonso Cardoso 6
}

\section{RESUMO}

Listeria monocytogenes é um bacilo que causa infecção em humanos com maior incidência durante a gestação, em pacientes imunodeprimidos ou com alguma doença de base grave, levando na maioria dos casos a meningite e bacteremia. A listeriose geralmente é assintomática, mas pode levantar suspeita em gestantes com sintomas de gripe, febre e dores no corpo. Com este trabalho foi possível concluir que a doença pode levar a graves comprometimentos como: derrames serosos, natimorto, aborto e até mesmo o óbito, podendo ser transmitida para o homem através da ingestão de alimentos contaminados pela bactéria. Tornando-se evidente somente através de testes sorológicos e isolamento de cultura sanguínea.

Palavras-chave: Listeria monocytogenes. Imunodeprimidos. Bactéria.

\section{ABSTRACT}

Listeria monocytogenes is a bacillus that causes infections in humans with higher indidence during pregnancy, or in immnosuppressed patients with serious underling diseases, leading in most cases meningitis and bacteremia. Listeriosis is usually asymptomatic, but may raise suspicion in pregnant women with flu symptoms, fever and body aches. With this work was concluded that the disease can lead to severe impairments as serous effusions, stillbirth, miscarriage and even death, can be transmitted to humans by eating foods contaminated with the bactéria. Becoming evident only through serological tests and blood culture isolation.

Kewords: Listeria monocytogenes. Immunocompromissed. Bacterium.

\footnotetext{
${ }^{6}$ Endereço eletrônico de contato: sandracardoso@hotmail.com
} 


\section{INTRODUÇÃO}

A Listeria monocytogenes é conhecida desde o início do século $X X$, mas só foi identificada como espécie bacteriana em 1940. O nome Listéria deriva do nome de Lorde Joseph Lister médico inglês, e o nome monocytogenes, é devido à capaciadade da bactéria de causar monocitose em coelhos. Existem várias espécies do gênero Listéria, entre elas, a Listeria monocytogenes é importante como causa de um amplo espectro de doenças em animais e no homem causando meningoencefalite e infecção generalizada em recémnascidos. ${ }^{(1)}$

Morfologicamente, a bactéria se apresenta sob a forma de bastonete Gram-positivo, delgado e curto, aeróbio, não formador de esporos, que algumas vezes ocorre como diplobacilo e em cadeias curtas, podendo se multiplicar sob ampla variação de temperatura (04 a $38^{\circ} \mathrm{C}$ ). São parasitas intracelulares ávidos que podem ser observados dentro da célula do hospedeiro em amostras de tecidos. As espécies dessa bactéria são catalase positivas e exibem uma motilidade característica por rolamento em meio líquido, que é mais ativa após o cultivo a $25^{\circ} \mathrm{C}$, podendo crescer, facultativamente, em uma variedade de meios enriquecidos. ${ }^{(2)}$

\section{Epidemiologia}

Listeria monocytogenes é a única espécie que infecta humanos, embora as outras espécies estejam disseminadas entre os animais e a natureza. As infecções por esse microrganismo podem ocorrer como casos esporádicos ou em pequenas epidemias e geralmente são veiculadas por alimentos contaminados. Estudos mostraram que 2 a $3 \%$ dos laticínios processados, 20 a $30 \%$ das carnes moídas e a maioria das amostras de carne de aves no atacado estão contaminadas com L. monocytogenes. ${ }^{(3)}$

Em gestantes, a doença é frequentemente adquirida no terceiro trimestre e sua importância se deve ao fato de poder causar morte fetal, aborto, parto prematuro e infecção neonatal. Sendo o diagnóstico realizado somente pelo isolamento do agente através do sangue, líquor, placenta ou tecidos do feto em meios de cultura comuns empregados na bacteriologia. $^{(2)}$ De 1 a $15 \%$ dos seres humanos hígidos são portadores intestinais assintomáticos da bactéria que após o contato torna-se um estado provisório de portador assintomático onde a doença pode desaparecer ou manifestar-se, principalmente como meningite ou bacteremia. ${ }^{(3)}$

Volume 1, Número 2 - Agosto, 2015. 
Em estudos epidemiológicos, são importantes nos esquemas desorotipagem e fegotipagem. O esquema atual de sorotipagem de Listeria baseia-se na identificação de 15 antígenos somáticos $(\mathrm{O})$ e cinco flagelares $(\mathrm{H})$, sendo 16 as sorovariedades reconhecidas para as cinco espécies do grupo um: $L$. monocytogenes, $L$. inoccua L. seeligeri, L. ivanovii ivanovii e L. ivanovii londoniensis, e L. welshmeri. O grupo dois é composto pelas espécies $L$. gravi que contém astígenos $\mathrm{O}$ e $\mathrm{H}$ específicos. Atualmente, existem 27 fagos para a tipificação de L. monocytogenes. ${ }^{(4)}$

A L. monocytogenes penetra no corpo através do trato gastrointestinal após a ingestão do alimento contaminado. Ela tem uma proteína de superfície na parede celular, a interleucina que interage com a caderina $E$, promovendo a fagocitose das células epiteliais. A bactéria migra de uma célula para outra sem se expor aos anticorpos. Através da corrente sanguínea dissemina-se por todo o organismo apresentando tropismo por células da placenta e sistema nervoso central. A imunidade contra o microrganismo é primariamente mediada por células, transferida por linfócitos sensibilizados, mas não por anticorpos. Os principais grupos susceptíveis à bactéria são pacientes imunocomprometidos ou com doença de base grave, gestantes e fetos. ${ }^{(5)}$

\section{Patogênese}

Listeria monocytogenes é um parasita intracelular facultativo que tem sido usado extensivamente para estudar a fagocitose e a ativação imune dos macrófagos. A bactéria fixase e penetra em uma variedade de células de mamíferos, aparentemente por fagocitose normal. Uma vez internalizada, escapa do vacúolo fagocítico elaborando uma toxina que lesa a membrana, denominada listeriolisina. O L. Monocytogenes se desenvolve no citosol e estimula alterações na função celular que facilitam sua passagem direta de uma célula a outra. Essa bactéria induz uma reorganização da actina celular, de modo que os filamentos curtos e as proteínas de ligação da actina aderem-se às bactérias criando uma cauda semelhante à de um cometa. Este complexo parece propelir as bactérias através da célula até os pseudópodes em contato com as células adjacentes. Fosfolipases bacterianas que degradam a membrana medeiam a passagem da bactéria para uma célula vizinha, permitindo que ela evite o meio intercelular e as células do sistema imune. ${ }^{(3)}$

\section{Significado clínico}

Volume 1, Número 2 - Agosto, 2015. 
A maioria dos casos de listeriose é esporádica e não apresenta sintomas ou se assemelham aos de uma gripe comum, dificultando assim o diagnóstico precoce da doença. As gestantes, geralmente, no terceiro trimestre podem apresentar um quadro semelhante ao de uma gripe fraca. Não existe um teste de triagem de rotina para a listeriose durante a gravidez, culturas de sangue são indicadas para gestantes com febre quando nenhuma outra patologia alternativa é prontamente detectada. Nos casos de colonização vaginal assintomática, a bactéria pode ser transmitida ao recém-nascido ou ao feto e iniciar um aborto. Os indivíduos imunodeprimidos, especialmente aqueles com imunidade celular deficiente, são susceptíveis as infecções sérias e generalizadas. ${ }^{(1)}$

Em função da baixa imunidade celular que ocorre principalmente nas primeiras semanas de gestação, as mulheres grávidas podem desenvolver rapidamente uma bacteremia por listeria. Esta bacteremia é manifestada clinicamente como uma doença aguda febril, frequentemente acompanhada por mialgias, artalgias, dor de cabeça e dores nas costas. A bactéria consegue proliferar em áreas de placenta não alcançadas pelos mecanismos de defesa usuais. ${ }^{(1)}$

Essa é provavelmente uma das causas da depressão da imunidade celular durante a gravidez aumentando a suscetibilidade à bactéria, esta podendo ser transmitida ao feto por via transplacentária ou mesmo durante o parto.

$\mathrm{Na}$ gestante os sintomas se assemelham aos de uma gripe normal, podendo apresentar sintomas gastrointestinais inespecíficos ou sintomas urinários. Quando a infecção ocorre nos dois primeiros trimestres de gestação quase sempre prenuncia a morte para o feto. No recém-nascido é a forma mais grave da doença. Pode ser precoce (adquirida intraútero) ou tardia (adquirida durante a passagem pelo canal do parto). A forma precoce tem alta mortalidade, manifesta-se nas primeiras horas após o nascimento por septicemia e acometimento do trato respiratório superior. A forma tardia ocorre duas a três semanas após o parto, sob a forma de meningite ou meningo-encefalite com septicemia. ${ }^{(6)}$

A Listeriose é rara em crianças e adultos imunocompetentes e relaciona-se principalmente ao sistema imune do indivíduo. Sua maior prevalência é relatada entre as classes socioeconômicas de maior poder aquisitivo devido ao consumo de alimentos industrializados e maior variedade a mesa, tornando a listéria um dos microrganismos que mais preocupam a indústria alimentícia. ${ }^{(1)}$

Por ser uma doença com alta incidência durante a gravidez e pela sua gravidade para o feto e recém-nascido, o diagnóstico correto e em tempo hábil da bacteremia materna pode prevenir a infecção neonatal,

Volume 1, Número 2 - Agosto, 2015. 
diminuído a sua mortalidade. O qual não é suspeitado frequentemente, devido à apresentação clínica pobre em sintomas específicos e à raridade do acometimento. Cerca de $20 \%$ das infecções perinatais resultam em natimorto ou morte neonatal onde o trabalho de parto prematuro é comum. ${ }^{(7)}$

O conhecimento das doenças febris que podem acometer a gestante e a investigação sistemática e minuciosa são importantes para realizar o correto diagnóstico sendo evidente somente através de exames laboratoriais como testes sorológicos e bioquímicos.

\section{Identificação Laboratorial}

$\mathrm{O}$ isolamento do agente é através do sangue, líquor, placenta, e outras amostras clínicas por procedimentos bacteriológicos padrões, em meios de cultura comuns empregados na bacteriologia como caldo triptona e tripticase-soja. Em Agar sangue, L. monocytogenes produz colônias pequenas circundadas por uma zona estreita de $\beta$-hemólise. As espécies de listeria podem ser diferenciadas de vários estreptococos pela morfologia, motilidade positiva e produção de catalase. L. monocytogenes tem sido isolada de diferentes alimentos, como leite cru e pasteurizado, queijos, carnes, produtos de origem vegetal, marinhos, não só em outros países, mas também no Brasil.(8)

\section{Tratamento e Profilaxia}

A ampicilina é considerada o medicamento de escolha no tratamento das infecções por L. monocytogenes. Este antibiótico pode ser ainda utilizado em associação a gentamicina, particurlarmente nos casos de bacteremia onde existe deficiência das funções das células $T$ e em todos os casos de meningite e endocardite. A bactéria é sensível à tetraciclina, eritromicina, cloranfenicol, sulfametaxazol, trimetropim, vancomicina e rifampicina. A duração do tratamento varia de duas a seis semanas. Nos últimos tempos houve um decréscimo na incidência da doença, devido ao melhor conhecimento de sua transmissão e aos cuidados preventivos introduzidos na indústria alimentar. ${ }^{(6)}$

Apesar de a $L$. monocytogenes ser um patógeno potencialmente perigoso, não existe ainda no Brasil, uma preocupação por meio das autoridades de saúde pública em relação a sua disseminação, por isso não há obrigatoriedades de sua notificação, nem há programas de conscientização da população quanto aos riscos do consumo de alimentos sem adequada industrialização e fiscalização. É preciso, portanto que ocorra um estímulo a pesquisas que

Volume 1, Número 2 - Agosto, 2015. 
possibilitem maior conhecimento sobre este microrganismo, assim como o desenvolvimento de métodos mais rápidos para sua detecção. ${ }^{(9)}$

No Brasil de acordo com a IN 9 existe um limite estabelecido para L. monocytogenes considerando sua gravidade estabelecendo ausência em $25 \mathrm{~g}$ na amostra do alimento. Com a finalidade de prevenir infecções por $L$. monocytogenes é necessário que haja um controle no local de processamento do alimento. A profilaxia é comprometida, uma vez que esta bactéria é encontrada distribuída amplamente na natureza e pode se desenvolver em ampla faixa de temperatura e $\mathrm{pH}$ como de 6 a 8 , grande resistência térmica, resistindo a vários congelamentos. No entanto, devem ser adotadas medidas que minimizem as chances de contaminação, como limpeza e sanitização dos equipamentos, evitar qualquer contato do produto final com a matéria prima, implantar um controle de qualidade na indústria como análise de perigos e pontos críticos de controle (APPCC), boas práticas de fabricação (BPF), programas de autocontrole que monitore os processos ambientais e também o pessoal. ${ }^{(10)}$

\section{CONCLUSÃO}

A listeriose é detectada principalmente no terceiro trimestre da gestação devido à sintomatologia ser inespecífica. Por ser uma doença com maior com maior incidência durante a gravidez e por sua gravidade para o feto, o diagnóstico em tempo hábil pode prevenir a infecção neonatal e até mesmo o óbito. O medicamento de escolha é a ampicilina com associação a gentamicina. Tendo em vista que o principal meio de contaminação é o alimento, devem ser adotadas medidas e cuidados, como evitar alimentos crus, lavar bem frutas e verduras antes de ingerí-las, cuidados com acondicionamento de carnes e matéria prima devem ser adotados, implantando controle de qualidade nas indústrias e fiscalização do ministério da agricultura.

Embora L. monocytogenes seja um microrganismo bastante estudado em países desenvolvidos, ainda há necessidade de mais estudos a fim de elucidar os diversos fatores que podem influenciar na sua patogenicidade, de acordo com o hospedeiro e o ambiente em que se encontra. Medidas que levam a um melhor controle da qualidade e higiene dos alimentos produzidos devem ser adotados pelas indústrias alimentícias reduzindo assim a contaminação pela L. monocytogenes. Deve-se ter maior informação e preocupação pelas autoridades e órgãos de saúde pública quanto aos sintomas específicos da bacteremia e outras doenças febris que podem acometer gestantes. Pois a L. monocytogenes é uma bactéria extremamente resistente, trazendo assim consequências graves e até irreversíveis.

Volume 1, Número 2 - Agosto, 2015. 
Em nosso país, assim como em outros em desenvolvimento, há carência de informações sobre esse importante patógeno. Assim, verifica-se a necessidade de intensificar e aprofundar a pesquisa de L. monocytogenes em amostras clínicas no Brasil, para que se possa dimensionar a real importância deste patógeno em nosso meio. Além disso, há necessidade de se tentar estabelecer a relação entre ocorrência de $L$. monocytogenes em amostras clínicas e o tipo de alimento consumido pelo paciente brasileiro, para buscar prevenir e controlar casos e surtos que possam vir a ocorrer.

\section{REFERÊNCIAS}

1. TRABULSI; Luiz Rachid; ALTERTHUM, Flávio Microbiologia dos alimentos. 5 ed. São Paulo: Atheneu, 2008.

2. SCHAECHTER, Moselio et al. Microbiologia: mecanismos de doenças infecciosas.3. ed. São Paulo: Guanabara Koogan,2009.

3. HARVEY, Richard et al.Microbiologia llustrada. 2 ed.Porto Alegre: Artmed, 2008.

4. COSTA, Yassanan de Souza. Microbiologia, parasitologia. 2. ed. Porto Alegre: Imprensa Livre, 1998.

5. FRAZZON, Jeverson et al. A resistência antimicrobiana e investigação de epidemiologia molecular de Listeria monocytogenes em produtos lácteos. Revista da Sociedade Brasileira de Medicina Tropical, Uberaba, v. 43, n. 4, 08 ago. 2010. Disponível em: $<$ http://wwwscielo.org/php/indec.php>

6. MOREIRA; Guilherme et al. Listeriose na gravidez. Revista Médica Minas Gerais, v 15, n 23, 03 abr. 2010. Disponível em: <http://wwwscielo.org/php/indec.php>

7. SECHWAB, Jussara Peres. Padronização técnica de imunocitoquímica para identificação de Listéria monocytógenes em placentas humanas. Revista Brasileira de Medicina Veterinária, Porto Alegre, v. 32, n. 2, 02 mar. 1998. Disponível em: $<$ http://wwwscielo.org/php/indec.php>

8. BARBOSA, André Victor et al. Susceptibilidade antimicrobiana de cepas humanas de Listeria monocytogenes isoladas no período de 1970 a 2008 no Brasil. Revista da Sociedade Brasileira de Medicina Tropical, Uberaba, v. 44, n. 2, 15 mar. 2011. $<$ http://wwwscielo.org/php/indec.php>

9. MELNIK, Jawetz; ADELBERG. Microbiologia Médica. 22 ed. Rio de Janeiro: Copright, 2005.

Volume 1, Número 2 - Agosto, 2015. 
10. TORRES, Adriana et al. Nova Legislação comentada de produtos lácteos. 3 ed. rev, ampl.e comentada. São Paulo Setembro editora, 2001.

Volume 1, Número 2 - Agosto, 2015. 